\title{
A Multi-Agent System Model Framework of Regional Technology Innovation Ecosystem
}

\author{
Wei Tie \\ Department of Technology Economy \\ Guangxi University \\ Nanning, China \\ weitie@gxu.edu.cn
}

\author{
Lei Lei \\ Department of Technology Economy \\ Guangxi University \\ Nanning, China \\ larainelei@hotmail.com
}

\begin{abstract}
It is a trend that complex science methods are involved more and more in the research of Regional Technology Innovation Ecosystem (RTIE). Considered advantages of Multi-Agent System (MAS) in complex system research, this paper explores the theory of modeling the RTIE in MAS method. It explains the appropriate of MAS application in RTIE, analyzes the basic modeling procedure and finally propose a MAS model framework of RTIE through system analysis, formalization description and operational process, which includes the conception and relation of Corporation Agent, Innovation Resources Agent, Regulation Agent and so on. It provides the theory and simulation foundation for a deeper research on RTIE and its complex adaptive changes.
\end{abstract}

Keywords-Regional Technology Innovation Ecosystem; Multi-Agent System;complex system modeling

\section{INTRODUCTION}

Since 1990s, with the fast development of globalization of world economy, regional technology innovation ability has increasingly become a key factor for countries and regions to obtain competitive advantages, which caused the attentions paid on Regional Technology Innovation System (RTIS) by many researchers. As the methodology of Ecology that emphasized the complex ecological characteristics was brought into this field, the research trend of Regional Technology Innovation Ecosystem (RTIE) was formed, as in [1].

Entering the 21 st century, the complex problems of RTIE appeared frequently. In the effect of frequent flows of global fund, technologies, human resources and other factors, it became more complicated of the relationship between different subjects in RTIE. This reflected in the endless phenomenon such as system self-organization and self-adaptive, also in the occurrence of system complex evolution with the changes of regional economy and policy. Thus using traditional research view became more and more difficult to deeply explain the complex evolution law of RTIE, and the introduction of complex system research perspective has become inevitable. In recent years, a Multi-Agent System (MAS) modeling method has been applied constantly in the complex system research, as in [2], and it uses the conception of intelligent agent to describe the interaction subjects in a complex system, then models based on the interaction between the agents and which with its environment, thus combining the micro behaviors of the agents and the whole system properties harmoniously, as in [3], and explaining somehow the evolution law of the complex system. Now, this method has been widely used in computer systems, supply chain and other complex natural and social science systems, as in [4]. However, the present research on RTIE using MAS modeling method are found scantily, so this paper intends to explore a way to modeling RTIE based on the MAS method, and establishes a MAS model framework of RTIE to provide a theory and simulation research foundation for RTIE and its complex adaptive changes.

\section{MAS MODEL AND CONCEPTION OF RTIE}

The concept of Agent comes from people's knowledge of artificial intelligence: the ultimate goal of artificial intelligence is to deal with affairs intelligently as an "Agency" who can replaces human being, as in [5]. With the research goes ahead, many models and theories are formed. In an extensive comprehension, the intelligent characteristic of Agent is embodied as the complex adaptive change according to the changes of complicated environment and subjects. As a result, MAS can be known as a complex system composed of many intelligent Agents with characteristics of complex adaptive change, as in [6] and [7]. According to these characteristics, rules of interaction between Agents and environment can be defined, then a MAS modeling process of RTIE available for computer simulation is established finally.

Cooke (1992) first puts forward the concept of Regional Innovation System (RIS), he considered that the RIS is a support and Innovation Regional organization consists of division and the associated individuals such as production enterprises, research institutes and universities, as in [8]. Since then, Wiggh and Wood (1995), Asheim and Isaksen (2002), Carlsson (1999), etc. discussed the concepts of RIS from different angles, as in [9][10][11]. These concepts basically extended the Cooke concept. At present, some scholars put forward some views into RTIS from the perspective of their researches, such as Lucheng Huang (2004) pointed out that the RTIS is an information and energy circulating system, cause different technology innovation subjects (enterprises, colleges and universities, research institutions, intermediary) and technology innovation environment (ecological, social, and economic), 
etc. in the system interdependence and interaction to create new material and new technology, in a certain region or country, as in [12]. Adner (2008) discussed the incubation conditions, integrated mechanisms and value characteristics of high-tech enterprises innovation ecosystem, as in [13]. Ming Qi and Xiaodan Lin (2009) raised a suggestion, developed a full-function and fullservice industry-university-research-officer combination of RTIE, to promote the regional comprehensive based on TRIZ theory, as in [14].

As some scholars have proposed many views of RTIE, according to the researches above, we define RTIE as which is a complex innovation ecosystem located in some certain region, consisted of interrelated multi-agents (enterprises, colleges, research institutes, government, etc.) and the environment surrounded them, where the agents change themselves adaptively according to the others' actions and the change of innovation resources(regional capital, technology, talents, information), and also affects and changes the condition at the same time. For that the innovation ecosystem evolution is occurred. So RTIE can be regarded as a typical MAS: a complex adaptive changing ecosystems including the Multi-Agent such as enterprises, colleges, research institutes, government, financial intermediaries, which have certain goals and behaviors and interact with the innovation conditions surrounded. That is also the main reason why we can establish a MAS model for RTIE.

\section{MODELING PROCESS}

According to the general procedure of MAS modeling, the basic process for establishing a MAS model of RTIS likes follows. The first step is analyzing the RTIE; the second step is abstracting Agent and conceptualization; the final step is establishing the Agent behavior model. The process of MAS modeling correspondingly is to analyze the real Agent system, conceptualize the Agent and establish operational computed Agent model. After completed MAS model, the further research of computer simulation and results analysis should be done based on it. The process of modeling above is shown as Fig.1.

Real Agent model is the observation, abstraction and analysis of the actual RTIE. Establish objective of the simulation by describing the behavior, rules, and interaction relationship between Agents. Concept Agent is the formalized definition and description of real Agent, and it is the design model according to the real Agent. Its properties include: behavior model Agent, internal state, Agent structure, interaction between the Agents and the environment. Computed Agent is the conversion of concept Agent into the operational computed model that can run and operate on computer program, is a formal description of the Agent model.

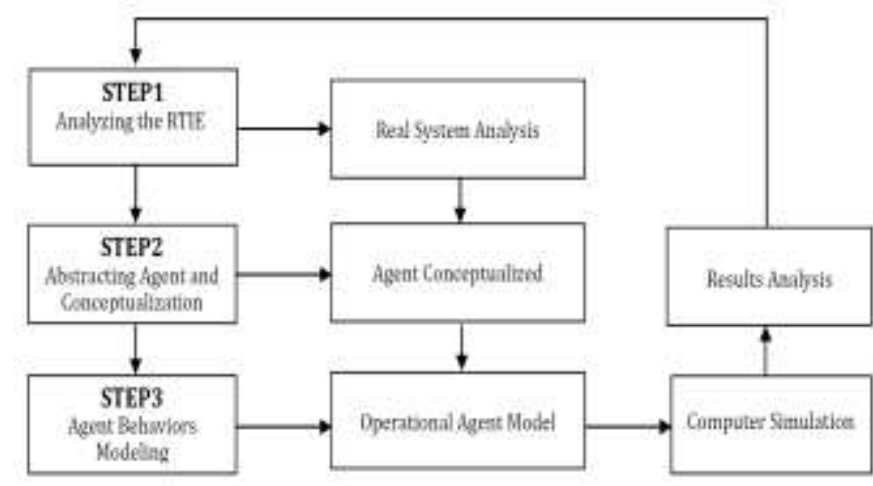

Figure 1. MAS modeling process of RTIE

\section{MAS MODEL OF RTIE}

\section{A. Analyzing the RTIE}

In the RTIE, innovation is the purpose and the driver of the whole system and enterprises, colleges, research institutes, government departments are the Agents in the RTIE. From the perspective of the system structure, three sectors can be divided, including enterprises innovation activities sector, innovation resources activities sector and control activities sector, as shown in Fig.2

In the enterprise sector, the enterprises carry out innovation activities. They interact with others through market competition or cooperation and achieve market value by imitating, learning and competition.

In the resource sector, colleges, research institutes, intermediaries and etc. provide technology, capital, talent and other important resources for technology innovation activities.

In the control sector, the government departments are the main controllers, their behaviors affect the overall changes of the whole system, such as the number of enterprises, the relationship between the enterprises, the strategies of enterprises innovations, innovation outputs, number of innovative talents and so on.

\section{B. Abstracting Agent and Conceptualization}

According to RTIE's structure divided above, all kinds of Agent are abstracted and conceptualized as follows.

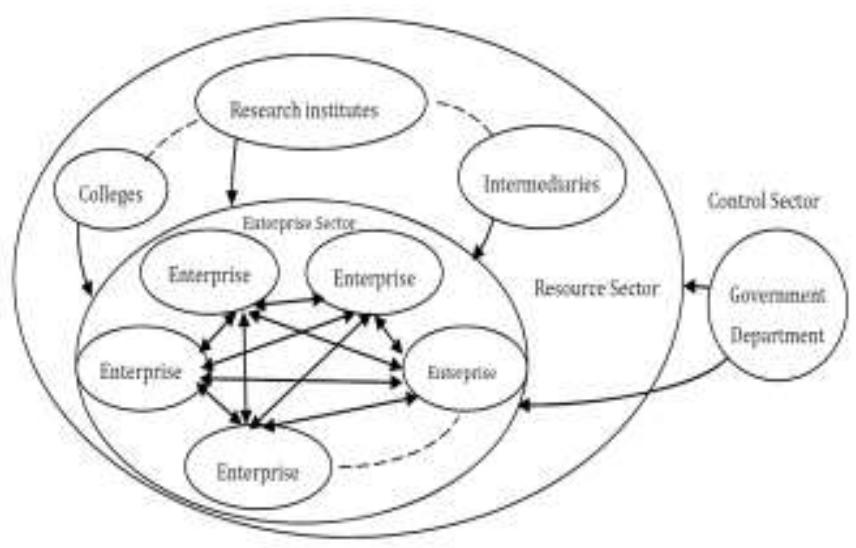

Figure 2. Structure of RTIE 


\section{1) Enterprise Agent}

Enterprises play an important role in the RTIE. They are not only the main agents of innovation, but also the most significance market agents. In addition, enterprises can self-adjust to ensure their best development in the complex environment, so they possess the individual adaptability of complex ecosystem. In the model, enterprise can be seen as a core Agent, and their behaviors are regarded as the most important factor of business decisions. Moreover, the activities between enterprises can be conceptualized as the overall reflection of the adaptive changes to the environment.

\section{2) Resource Agent}

In RTIT, innovation resources always include talents, technology, funds and so on. In reality, innovation resources are supplied by research institutes, colleges, enterprises, governments, and individuals. Innovation resource could be changed to satisfy the system requirements possibly according to the resources demand for innovative activities. Therefore, resource can be seen as an Agent, because of its complex adaptability.

\section{3) Control Agent}

Control Agent mainly includes the government departments of science and technology management, enterprise's innovation strategy departments which made policies to effect the system. They could made policies and supply measures to improve the system's development according to the changes of system resources and enterprise's activities. For this reason, it is also an Agent having the complex adaptive features.

In brief, the Agents and their behaviors are conceptualized in Table 1.

\section{TABLE I. MULTI-AGENT IN RTIE}

\begin{tabular}{|l|l|l|}
\hline \multicolumn{1}{|c|}{ Agent } & \multicolumn{1}{c|}{$\begin{array}{c}\text { Real } \\
\text { representative }\end{array}$} & \multicolumn{1}{c|}{ Basic behavior } \\
\hline Enterprise & $\begin{array}{l}\text { Variety of different } \\
\text { sizes and different } \\
\text { types enterprises }\end{array}$ & $\begin{array}{l}\text { - Collect available innovation } \\
\text { resources in the system } \\
\text { - Modify internal environment } \\
\text { according to environmental } \\
\text { changes } \\
\text { - Analyze and evaluate } \\
\text { innovation behavior } \\
\text { - Decide innovation activities }\end{array}$ \\
\hline $\begin{array}{l}\text { Resource } \\
\text { Agent }\end{array}$ & $\begin{array}{l}\text { Capital, technology, } \\
\text { talent, information } \\
\text { and so on. }\end{array}$ & $\begin{array}{l}\text { - Active innovation. } \\
\text { - Restrict innovation } \\
\text { - Self-change according to } \\
\text { innovation needs }\end{array}$ \\
\hline Control & $\begin{array}{l}\text { Relevant } \\
\text { Agent } \\
\text { government } \\
\text { departments, } \\
\text { enterprise } \\
\text { innovation strategy } \\
\text { departments. }\end{array}$ & $\begin{array}{l}\text { Monitor number of enterprises } \\
\text { - Monitor number of innovation } \\
\text { resources } \\
\text { - Monitor innovation resources } \\
\text { allocation } \\
\text { - Coordinate relationship } \\
\text { between Agents } \\
\text { - Manage and supervise } \\
\text { innovation activities }\end{array}$ \\
& & $\begin{array}{l}\text { Make policies to promote } \\
\text { innovation } \\
\text { - Maintain the RTIE stable. }\end{array}$ \\
\hline
\end{tabular}

\section{Agent behavior model of RTIE}

Behaviors of different Agents and their interaction process are described as follows.

\section{1) Step 1}

Enterprise Agent accepts two aspects of information, one is from Resource Agent, and the other is from Control Agent. Enterprise Agent makes decisions whether to innovate or not after evaluating the information. Once to innovate, it will affect the changes of Resource Agent.

2) Step 2

Resource Agent also accept information from two aspects, i.e. Enterprise Agent and Control Agent. It makes innovation strategy according to its rule, which will support or restrict the enterprise's innovation activities. And thus the resources distribution could be changed. At the same time, the information of Resource Agent's state changes feeds back to Enterprise Agent, then the Enterprise Agent will repeat the action as step 1 accordingly.

3) Step 3

The action information of Enterprise Agent and Resource feeds back to Control Agent, and Control Agent makes decisions according to the changes of enterprise and resource, publishes the policies to affect the Enterprise Agent and Resource Agent. Then the action is repeated as step 1 and step 2 above.

This Multi-Agent interaction process model is shown in Fig.3.

In this model, different Agent has their code of conduct, but it is consistent that Agents have the ability of receiving other information from different Agent, making decisions and judgment, performing corresponding behavior reaction to others. Only Agent have done innovation, can other Agent stimulated, also is only innovation can have a positive impact on the RTIE. While Enterprise Agent innovation impact on other Agent, has a direct impact on itself. In general, innovations promote the interaction constantly.

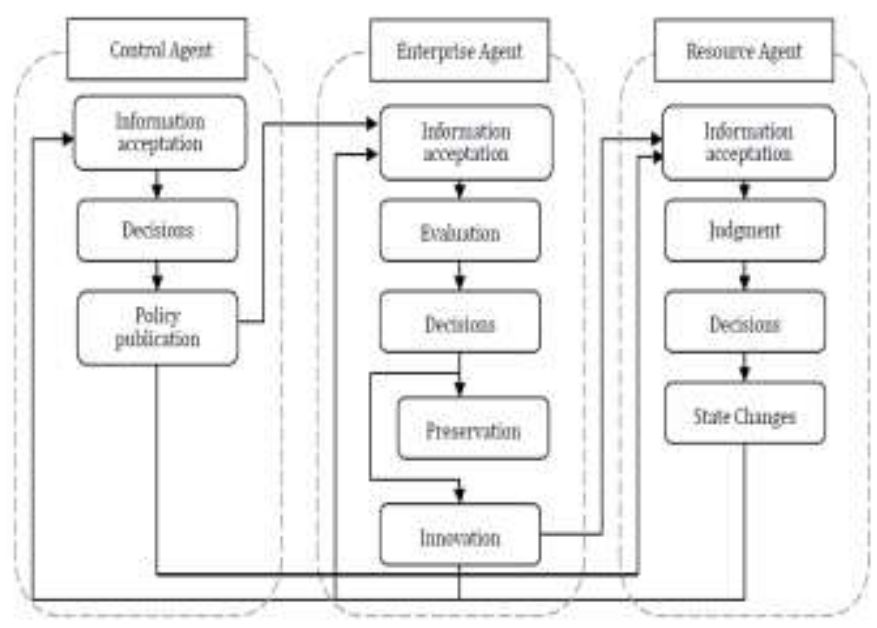

Figure 3. Multi-Agent behavior model of RTIE 


\section{CONCLUSION}

In conclusions, we discuss the framework for establishing a MAS model of RTIE and come out with some main opinions as follow:

Firstly, the procedure of MAS modeling for RTIE includes three steps, including analyzing the RTIE, abstracting Agent and conceptualization, and establishing the Agent behavior model.

Secondly, the structure of RTIE can be divided into three sectors, i.e. enterprises sector, innovation resources sector and control sector, which lead to the abstraction and conception of Enterprise Agent, Resources Agent and Control Agent respectively.

Finally, a Multi-Agent interaction model of RTIE is established. It shows that the development and evolution of RTIE can be regarded as a process passing and distributing innovation resources in multi-agents, leading to an overall changes in the ecosystem.

From research, we argue that the development and evolution of RTIE can be regarded as a process through passing and distributing innovation resources in each Agent to complete Agent cooperation exchanges for achieving holistic changes of RTIE. The ideas and the whole modeling process provide important basic theory for further researches of complex adaptation mechanism and evolution simulation of RTIE.

\section{ACKNOWLEDGMENT}

This work was financially supported by the National Natural Science Foundation of China (NO: 71162025).

\section{REFERENCES}

[1] Lucheng Huang, "The characteristics of Regional Technology Innovation Ecosystem," Forum on Science and Technology in China, vol.1, Jan. 2003, pp.23-26.
[2] Zhiliang Huang, "Regional Innovation System theory and it application research review, " Contemporary Economy Research, vol.8, Aug. 2008, pp.21-25.

[3] Ling Xue, Kaizhong Yang, "Model reasearch on Multi-Agent of city evolution," Systems Engineering-Theory \& Practice, vol.33, Dec. 2003, pp.1-9.

[4] Tianchen Huang, Jingcai Han, "Analysis and modeling of complex adaptive system based on Agent technology," Computer simulation, vol. 22, Jun. 2005, pp.58-60

[5] Horling B, Lesser V, "A survey of multi- agent organizational paradigms," UMass Computer Science Technical Report, vol.4, May. 2004, pp.223-231.

[6] Miquel M, Beatriz L, "Developing trust in recommender agents," Proceedings of Autonomous Agents and Multi-Agent Systems, Aug. 2002, pp.304-305.

[7] Delre S, Jager W, Bijmolt $\mathrm{T}$, et al. "Targeting and timing promotional activities: an agent-based model for the takeoff of new products," Journal of Business Research, vol.60, Aug. 2007, pp.826-835.

[8] Cooke P, "Regional Innovation Systems: competitive regulation in the new Europe," Geoforum, vol.23, Jul. 1992, pp.365-382.

[9] Wiigh H,Wood M, "What comprises a regional innovation system: an empirical study," Gothenburg,Sweden, vol.212, Aug. 1995, pp.112-117.

[10] Asheim T. Isaksen, "Regional Innovation Systems: the integration of local stick and global ubiquitous knowledge, The Journal of Technology Transfer, vol. 27, Feb. 2002, pp.77-86.

[11] Carlsson B, Jacobsson, Staffan A, et al. "Innovation Systems: analytical and methodological issues," Paper for DRUID's Innovation Systems Conference, May. 1999, pp.65-71.

[12] Lucheng Huang, "The regulating mechanism in the Regional Technology Innovation Ecosystem," Journal of Systemic Dialectics, vol.14, Feb. 2004, pp.69-71.

[13] Adner R, "Match your innovation strategy to your Innovation Ecosystem," Harvard Business Review, vol. 84, Dec. 2008, pp.98107.

[14] Ming Qi, Xiaodan Lin, "Discuss the construction of Regional Innovation Ecosystem based on TRIZ," Science and Technology Management Research, vol.16, Sep. 2009, pp.444-446. 